\title{
The status of alien bamboos in South Africa
}

\author{
Susan Canavan ${ }^{\mathrm{a}, \mathrm{b}, \mathrm{c}, *}$, David M. Richardson ${ }^{\mathrm{b}}$, Johannes J. Le Roux ${ }^{\mathrm{b}, \mathrm{d}}$, Scot A. Kelchner ${ }^{\mathrm{e}}$, \\ John R.U. Wilson ${ }^{\mathrm{a}, \mathrm{b}}$ \\ a South African National Biodiversity Institute, Kirstenbosch Research Centre, Cape Town, South Africa \\ ${ }^{\mathrm{b}}$ Centre for Invasion Biology, Department of Botany and Zoology, Stellenbosch University, Stellenbosch, South Africa

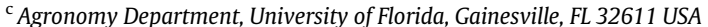 \\ ${ }^{\mathrm{d}}$ Department of Biological Sciences, Macquarie University, Sydney, New South Wales 2109, Australia \\ e Department of Biology, Utah State University, 5210 Old Main Hill, Logan, UT 84322-5210, USA
}

\section{A R T I C L E I N F O}

\section{Article History:}

Received 6 August 2020

Revised 9 November 2020

Accepted 11 November 2020

Available online $\mathrm{xxx}$

Edited by GV Cron

\section{Keywords:}

Biological invasions

Invasion science

Plant invasions

Risk analysis

Tall-statured grasses

\begin{abstract}
A B S T R A C T
The growing interest in commercial cultivation of bamboos (Poaceae subfamily Bambusoideae) has led to the introduction of new alien species into South Africa. The rate at which bamboos are being planted in South Africa is a cause for concern because of the impacts of bamboo invasions in other parts of the world. To understand the risks associated with new introductions and new plantings, we assess the outcomes of past introductions of bamboos into South Africa. To this end we: (1) produce an inventory of alien bamboo taxa; (2) assess the distribution of bamboos; (3) determine the rate of spread of bamboo at a site with a high density of naturalised stands; and (4) evaluate the current regulatory status of alien bamboos in South Africa. We used a combination of expert opinion, literature, historical records of populations, and public participation to produce a species list and locate populations of alien bamboos. We also attempted to confirm species identities using DNA barcoding. We found that 28 currently-accepted species of bamboo have been recorded in South Africa. However, we have little confidence in this estimate, as 20 of the species could not be confirmed or identified as present in the country. Bamboos are an inherently challenging group to identify using vegetative material, and DNA barcoding was inconclusive. The distribution of bamboos across the country varied with the type or lineage (e.g. herbaceous, tropical or temperate) and the source of information (e.g. herbarium records, in-field observation or public contribution). Although alien bamboos are naturalised at several sites, we found no large invasive stands nor evidence of widespread negative environmental impacts. Nonetheless, we recommend caution regarding future introductions of bamboos for commercial cultivation, as the nature of the plantings will likely differ from the historical situation in both the location, configuration, and the scale of cultivation, and as new species are likely to be introduced. We propose several changes to the current listing of bamboo taxa in national legislation pertaining to alien and invasive species.
\end{abstract}

(C) 2020 SAAB. Published by Elsevier B.V. All rights reserved.

\section{Introduction}

In the last decade, there has been a major drive to promote the cultivation of bamboo species (taxa in Poaceae subfamily Bambusoideae) in South Africa. As South Africa only has one native bamboo species, Bergbambos tessellata (Nees) Stapleton, non-native bamboos are being sought for various horticultural and agricultural purposes. In particular, fast-growing and hardy bamboo species from Asia are being used as feedstock for bioenergy and biofuels, for pulp and paper production, for phytoremediation, and to provide general construction material (Scheba et al., 2017). However, widespread bamboo introductions and plantings have resulted in damaging invasions

\footnotetext{
* Corresponding author at: Agronomy Department, University of Florida, Gainesville, FL 32611 USA.

E-mail address: sucanavan@gmail.com (S. Canavan).
}

elsewhere in the world (Canavan et al., 2016, 2019a). Therefore, an assessment of the current status of bamboos is urgently needed as part of a comprehensive analysis of risks associated with bamboo cultivation in South Africa. Despite the country's long history with bamboo introductions (Visser et al., 2017; Canavan et al., 2019b), there has been no detailed assessment to determine which species have been introduced, whether any species have become invasive, what the current distribution of species is or which species should be regulated.

A clear understanding of the status of alien taxa is fundamental to projecting future risks and the role of invasion debt in driving invasions of the future (Rouget et al., 2016). Even well-studied taxa of alien plants in South Africa, e.g. Australian acacias (genus Acacia Martius), have been found to have outdated, inaccurate or incomplete species lists (Magona et al., 2018). Alien grasses tend to have been poorly studied compared to other taxa in South Africa 
(Visser et al., 2017). Milton (2004) published the first review of alien grasses in South Africa; this included a list of 114 grass taxa known to be present in the country, including one species of bamboo (Bambusa sp.). In an updated assessment, Visser et al. (2017) listed an additional 143 alien grass species (a total of 256 species), including 17 species of bamboo. These authors concluded that 11 of the 17 species of bamboos were probably introduced prior to the 1950s, some as early as 1866 (e.g. Bambusa balcooa Roxb.).

As of October 2020, only one bamboo taxon - listed as Sasa ramosa (Makino) Makino \& Shibata - is recorded as present in the country and requiring control under South Africa's Alien and Invasive Species Regulations of the National Environmental Management: Biodiversity Act (NEM:BA, Act 10 of 2004, hereafter the NEM:BA A\&IS Regulations and Lists). It is listed as category 3 which means that propagation and selling is prohibited, although, existing plantings can remain until they die out. Another taxon -the genus Arundinaria Michx - is included in the NEM:BA A\&IS Lists of 2016 as being absent from South Africa and prohibited from being imported. Two different species (Bambusa balcooa and Olyra latifolia L.) were listed among 759 taxa of naturalised plants for the country (Richardson et al., 2020). There are several possible reasons for the low representation of bamboos on these lists. It may be because the current levels of impacts do not reflect the potential future impact [there is often a lag of several decades between introductions, invasions, and impacts (Rouget et al., 2016)]; bamboos do not pose a significant invasion risk to South Africa; or that alien bamboos have simply been understudied.

To provide baseline information to analyse the risks associated with alien bamboos and their cultivation in South Africa this paper sets out to: (1) compile an updated inventory of the alien bamboo species present in South Africa; (2) assess the distribution of bamboos in South Africa from historical records and field observations; (3) determine invasive status at a key site with a high density of bamboos; and (4) provide recommendations as to which species should be regulated and how.

\section{Methods}

\subsection{Compiling a list of alien species and their distribution}

Various sources were used to compile a list of alien bamboo taxa present in South Africa (Fig. 1), including: (1) records obtained from online literature searches in Google Scholar (terms searched: Bamboo OR Bambusoideae AND South Africa); (2) herbarium records and data from the Southern African Plant Invaders Atlas (date accessed: 20 June 2020) - a national atlas project on the distribution of invasive alien plants (Henderson and Wilson, 2017); (3) the National Herbarium Computerised Information System [PRECIS online database http://newposa.sanbi.org/; Morris and Glen (1978)]; (4) herbarium records for South Africa listed on the Global Biodiversity Information Facility (GBIF, 2016), an open access source of global biodiversity data; and (5) iNaturalist (http://www.inaturalist.org), a citizen science project (See Supplementary Material 1). We removed duplicate data and filtered incomplete information. Synonyms were corrected using The Plant List (www.theplantlist.org accessed in October 2019).

We also undertook field surveys across South Africa (see Fig. 1a) to identify species and populations not previously recorded. To locate populations we: (1) sought advice from local and regional conservation managers or experts working with invasive species; (2) compiled information from herbaria records (from the sources mentioned above); (3) posted articles in agricultural magazines appealing to the public for information on sites where bamboos were growing; and (4) distributed an online questionnaire on social media (See Canavan et al., 2019b and Supplementary Material 2 for more information). At each sampling site photographs were taken of the site and of key morphological features of the bamboo recorded. Where possible, herbarium samples and fresh undamaged leaves were collected for genetic analysis (see below). Sampling was conducted intermittently between 2014 and 2016.

Bamboos belong to three evolutionary lineages that are reflected in the modern taxonomic classification (Bamboo Phylogeny Group, 2012): tribe Bambuseae ('tropical'), tribe Arundinarieae ('temperate'), and tribe Olyreae ('herbaceous'). Although there are some exceptions, the three tribes can generally be distinguished by growth form: 'clumping' (tropical), 'running' (temperate, with leptomorph rhizomes), and herbaceous, which lack 'woodiness' and are of low stature. For the purpose of this paper, we use these classifications (temperate, tropical, and herbaceous) to group South African bamboos into 'lineages'.

\subsection{Identification and DNA barcoding of species}

DNA barcoding is an increasingly important component of biosecurity to identify alien species and is particularly useful for taxa that are not easily identifiable using morphological characteristics alone (Armstrong and Ball, 2005), as is the case with bamboos. The use of morphological characteristics in bamboo taxonomy is challenging as morphological identification is usually dependent on reproductive features and as inflorescence and seed production are infrequent in many woody bamboos.

Therefore, to aid the identification of our collected samples, we used DNA barcodes from one chloroplast region. We used the primer set D4 which was developed for amplification across flowering plant groups and was specifically tested on bamboos (Watts et al., 2008). The D4 primers target a highly variable rpl16 intron chloroplast region which is well represented for bamboos in the online GenBank repository (https://www.ncbi.nlm.nih.gov/genbank/). It has good, or higher, resolution in bamboos than the commonly used trnD-trnT intergenic spacer (Watts et al., 2008).

DNA extractions of collected leaf material were done using a modified version of the cetyltrimethylammonium bromide (CTAB) method as described by Doyle and Doyle (1990). Preserved and dried leaf tissue samples ( $300 \mathrm{mg}$ ) were ground using a TissueLyser. $1 \mathrm{ml}$ of CTAB extraction buffer was added to each sample and held at $65^{\circ} \mathrm{C}$ for $60 \mathrm{~min}$. To extract DNA, $200 \mu \mathrm{l}$ of chloroform:isoamyl alcohol (24:1) was added $(2 \mathrm{x})$, and precipitated using $600 \mu \mathrm{l}$ of chilled isopropanol. DNA pellets were drained and washed using $1 \mathrm{ml}$ of $70 \%$ ethanol. Samples were dried overnight and then re-suspended in $50 \mu \mathrm{l}$ of MilliQ water. DNA concentrations were determined using a NanoDrop spectrometer (ND1000).

The rpl16 intron was amplified using the primers R1516 and sak16F (Watts et al., 2008) with the following polymerase chain reaction (PCR) conditions: Initial denaturation at $80^{\circ} \mathrm{C}$ for $5 \mathrm{~min}$, followed by 35 cycles of denaturation at $95{ }^{\circ} \mathrm{C}$ for $1 \mathrm{~min}$, annealing $(1 \mathrm{~min}$ ramp of $0.3{ }^{\circ} \mathrm{C} / \mathrm{s}$ starting at $\left.50{ }^{\circ} \mathrm{C}\right)$, and extension $\left(1.5 \mathrm{~min}\right.$ at $\left.65{ }^{\circ} \mathrm{C}\right)$, and a final extension $\left(4 \mathrm{~min}\right.$ at $\left.65^{\circ} \mathrm{C}\right)$.

Each $30 \mu \mathrm{l}$ reaction contained ca. $300 \mathrm{ng}$ of genomic DNA, $200 \mu \mathrm{M}$ of each dNTP (Thermo Scientific, supplied by Inqaba Biotec, Pretoria, South Africa), 3 pmoles of each primer, 1 U Taq DNA polymerase (supplied by Separation Scientific SA), 1X PCR reaction buffer and $2 \mathrm{mM} \mathrm{MgCl}$.

PCR products were run on a $1 \%$ agarose gel and visualised under UV light. Amplified DNA fragments were purified using the QIAquick PCR Purification kit (Qiagen, supplied by Whitehead Scientific, Cape Town, South Africa), and sequenced using the ABI PRISM BigDye Terminator Cycle Sequencing Ready Reaction kit (forward only) and an automated ABI PRISM 377XL DNA sequencer (PE Applied Biosystems, Foster City, CA, USA) and the forward primer used for PCR amplification.

To determine taxonomic resolution, we did an initial BLAST search of three test samples that represented three different genera (from both temperate and tropical bamboo lineages). 


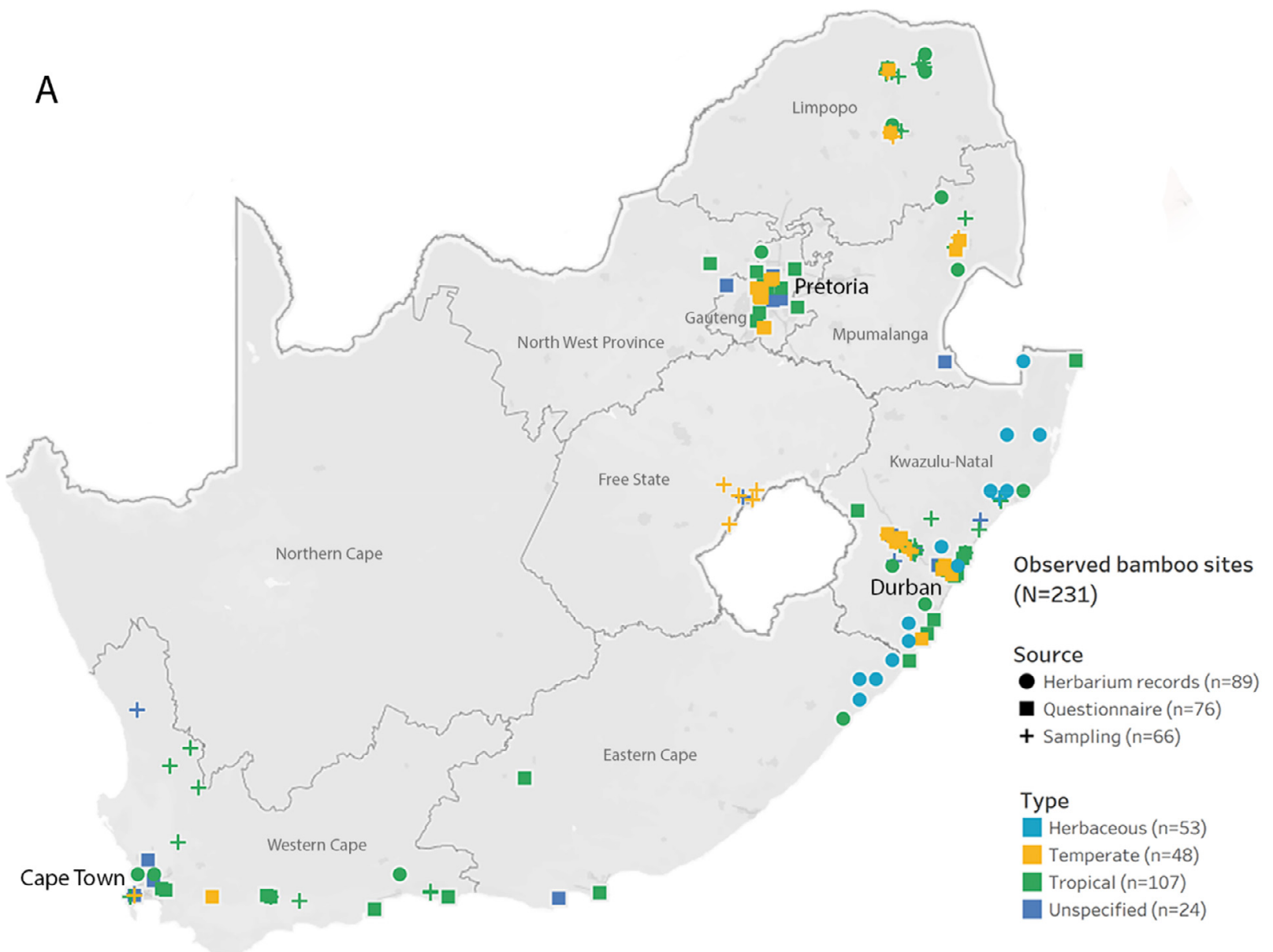

B Timeline of bamboo populations recorded in South Africa

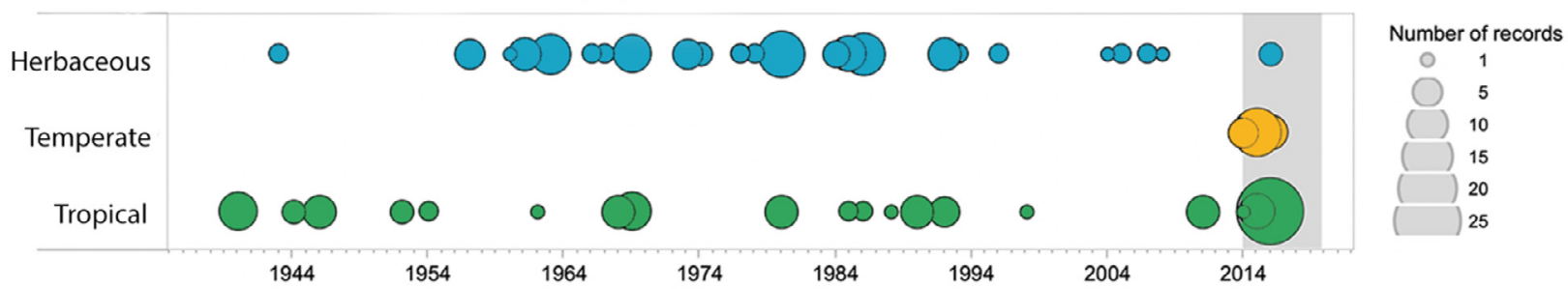

Year of record

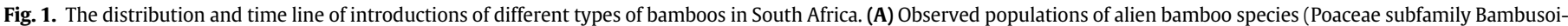

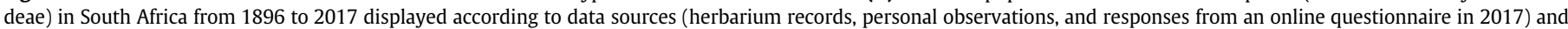

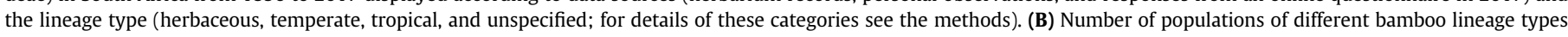
recorded in South Africa between 1940 and 2016. Information comes from herbaria records and observations made during this study (grey shaded area).

\subsection{Assessing invasion rates of bamboos along the Nonoti river}

During field surveys, the only site where we observed dense clumps of bamboo was along from the Nonoti river in KwaZulu-Natal, from about ten kilometres inland to its estuary (Fig. 2). These clumps likely originated from historic plantings by sugarcane farmers for windbreaks and erosion control [this part of KwaZulu Natal is a productive sugarcane growing region (Platford 1988)]. The river itself is small but leads to the Nonoti estuary, one of eight estuaries of the
KwaDakuza river system, which supports unique biodiversity. If bamboos are spreading in this area, the functioning and diversity of this important ecosystem could be threatened.

To assess changes in the extent of the bamboo clumps, we compared satellite images on Google Earth taken in 2006 with images taken in 2017. Tropical bamboos at this site are easily distinguishable from the background vegetation due to their large size, colouration, and rounded form. We could therefore identify and draw polygons around clumps or groups of clumps $(n=96)$. We measured all clumps 

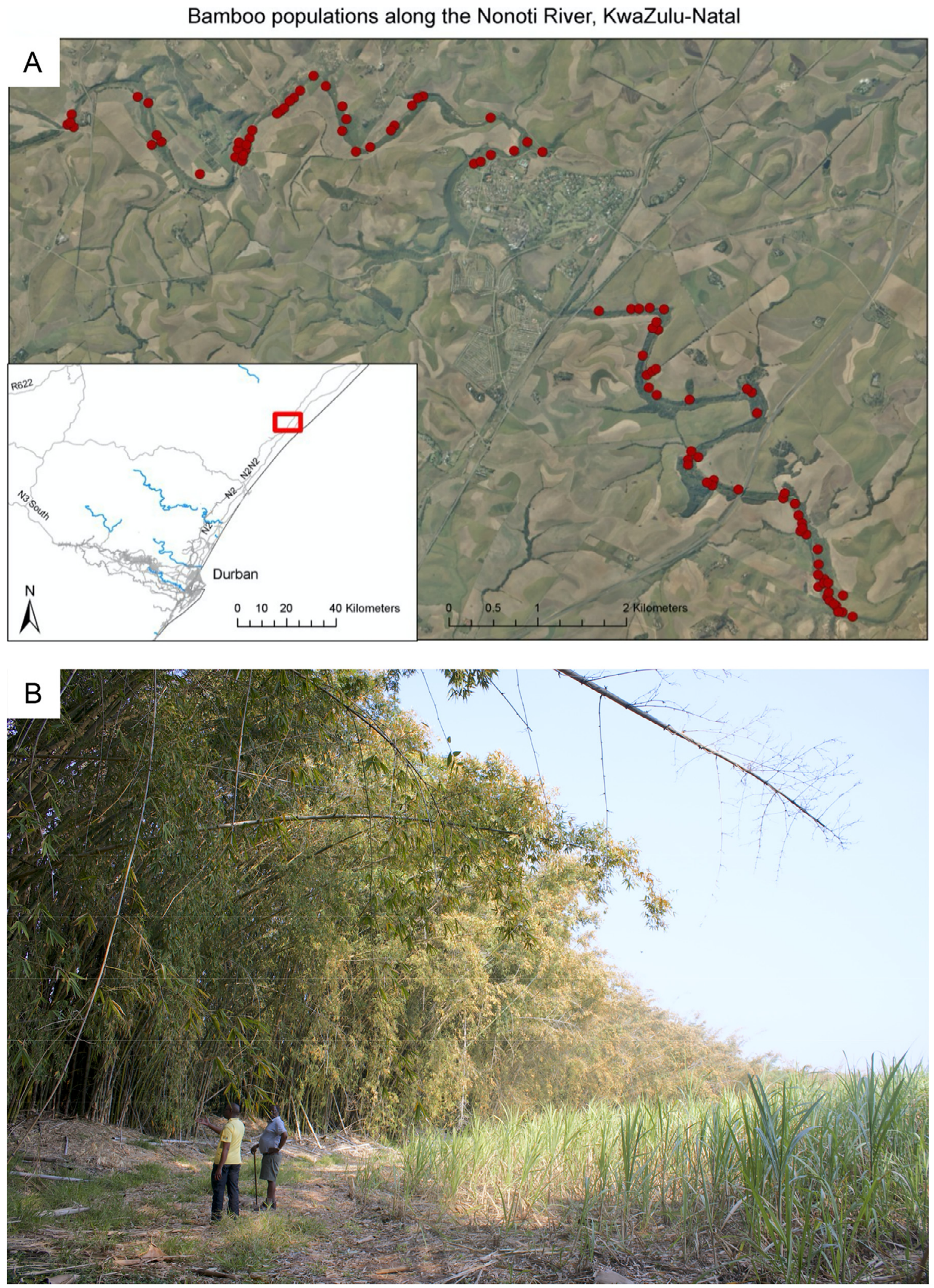

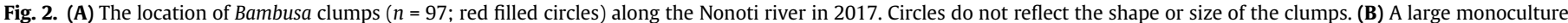

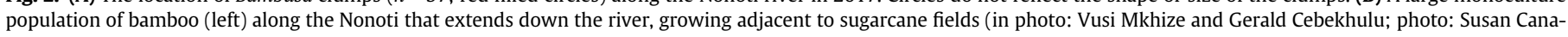
van).

that were within $160 \mathrm{~m}$ of both sides of the Nonoti River. We identified and marked bamboos from the base of the estuary until populations became sparse (less than one observation per kilometre along the river way). The last bamboo clump measured was roughly $10 \mathrm{~km}$ inland from the coast, where the Gunqu river joins the Nonoti river $\left(-29.257242^{\circ}, 31.307501^{\circ}\right)$. We used Google Street View to confirm that some mapped clumps were indeed bamboos. We additionally referenced images of sites that were physically sampled with those 
on Google Earth to confirm they matched. We used the website Earth Point (www.earthpoint.com) to calculate the area of all measured polygons. The total area occupied by bamboos is likely a conservative estimate, as we might have missed smaller nascent clumps and other clumps that occur under dense tree cover. Although manual delineation of bamboo clumps using the polygon tool provides crude estimates, the level of error is likely to be similar for the sets of images taken in 2006 and 2017.

Data for both the 2006 and 2017 images were not normally distributed according to a Shapiro-Wilk normality test $(W=0.15521$, $p<0.001$ ). We therefore used a paired Wilcoxon Signed-Rank Test to determine whether the areas of the different populations differed significantly in 2006 compared to 2017. All analyses and data visuals were done in R 3.4.3 ( $R$ Core Team 2015).

\subsection{Developing regulatory recommendations}

Because the reasons for listing taxa in the NEM:BA A\&IS Regulations are not clearly documented (Kumschick et al., 2020a), we reevaluated currently listed bamboo species. We also assessed Phyllostachys aurea Rivière \& C.Rivière, which is not listed but poses a threat as it is present in South Africa and invasive in many parts of the world (Canavan et al., 2016). Moreover, $P$. aurea was observed to escape perimeters of gardens across the country, more so than other bamboos. Landowners also complained about this bamboo being more problematic (like other "running" bamboos that have leptomorphic rhizomes) than clumping (pachymorph) species, which are considered less weedy (Canavan et al., 2019b). We, therefore, conducted specieslevel risk analyses on Sasa ramosa and Phyllostachys aurea using the framework developed by Kumschick et al. (2020b). A genus-level risk analysis was not conducted on Arundinaria as proposed amendments to the NEM:BA A\&IS Regulations also published in 2018 (and due to come into force on 1 March 2021) removed the prohibited list.

\section{Results}

\subsection{Introduction and presence of bamboo}

The literature search and herbarium records revealed 28 species of bamboos (Table 1) that are recorded as having been introduced to South Africa (Platford 1988). The actual number of alien bamboos in the country is, however, probably higher given the recent upsurge in species being imported for experimentation by private growers, and as many of these introductions have not been documented or declared (S. Canavan, pers. obs.). We also observed that the species and lineages that have been recorded and introduced have changed over time (Fig. 1b). Specifically, there have been more historical introductions of large tropical species, whereas recently there are more records of invasive temperate species.

We recorded 66 sites across South Africa with alien bamboo populations (Fig. 1). Bamboos are currently distributed in all provinces of the country except the Northern Cape, although there were only a few records from the Eastern Cape. Some sites were sampled multiple times as several species were present. A large number of sites (56\%) were located through suggestions from the public and experts who responded to postings about the project on social media, magazines and email chains (Fig. 1a; see Canavan et al., 2019b); specifically, 16 sites were suggested by local and regional conservation managers or experts working with invasive species and 19 sites were from the general public. 35\% $(n=23)$ of sites were located during sampling efforts but were non-targeted, and eight sites were found after consulting herbarium records. One site was excluded as the species found there was determined to be the native bamboo species Bergbambos tessellata.

Almost half ( $48 \% ; n=32$ ) of the sites were on a private land such as smallholdings, farms or business premises; $47 \%(n=31)$ were on public land such as road verges, waterways or government-owned sites including nature reserves and forestry plantations. Another three sites were established commercial bamboo plantations. More than half of the sites $(54 \% ; n=36)$ had populations that had escaped cultivation (found beyond the property perimeter of the original planting site) or appeared to be naturalised in that they had self-sustaining populations beyond cultivation. The remaining populations were in gardens or farms and appeared to be planted and cultivated $(46 \% ; n=31)$. When we grouped the sampled populations by lineage (Fig. 1a) as designated by Kellogg (2015), half of the populations comprised tropical species $(49 \% ; n=33)$, and $39 \%$ were temperate $(n=26)$, one site had a herbaceous bamboo, and the remaining sites had multiple lineages $(n=3)$ or the lineage was unknown $(n=4)$. Responses from the online questionnaire, and from our sampling efforts, indicated the prevalence of temperate species in urban sites, whereas herbarium observations indicated only the presence of tropical and herbaceous species.

Bamboos were found across a range of altitudes from $33 \mathrm{~m}$ to $1700 \mathrm{~m}$ above sea level. Temperate bamboos tended to occur at higher altitudes on average $(1231 \mathrm{~m})$ compared to tropical species $(583 \mathrm{~m})$. No populations were observed to be flowering or seeding. Some landowners mentioned that they had seen flowering (in what is suspected to be Bambusa balcooa), but we were unable to confirm this. We noted that populations were typically close to water sources.

\subsection{Identification of species}

We were unable to reliably identify our samples to the species level because our specimens lacked reproductive structures, and there is no regional taxonomic expert specialising in bamboo. We were, however, able to group populations by the lineage (temperate, tropical or herbaceous), with the exception of four sites. The lineage is related to the growth form, with temperate species having a running form with woody culms, and tropical also having woody culms but growing in a clumping manner; herbaceous species are smaller and more grasslike. Temperate species spread rapidly compared to clumping tropical species, separating bamboos by growth form is therefore, an important indicator of invasion potential (Lieurance et al., 2018).

We were able to successfully sequence the rpl16 region. However, we were unable to confindently assign taxonomic identitiesies to our sampled bamboos based on the BLAST results. For example, we retrieved a perfect DNA sequence similarity match (100\%) with multiple species from different genera and even different lineages. This shows that there is low resolution between species for this DNA region and that this approach is not appropriate for identifying bamboos to the species or even genus level.

\subsection{Invasion rate at the Nonoti river site}

There was a significant increase in the area of Bambusa balcooa (suspected species) clumps between 2006 and $2017(V=1524$, $p<0.01$ ), although the rate of expansion was slow. In 2006, bamboo clumps occupied an estimated total area of $175,456 \mathrm{~m}^{2}$. By 2017 , there had been a $6 \%$ increase in area (total area $186,454 \mathrm{~m}^{2}$ ). Individual bamboo clumps increased in size at a rate of $2.52 \mathrm{~m}$ over 11 years or $<0.3 \mathrm{~m}$ a year, on average. However, not all sites showed an increase in size; of the 95 clumps, 61\% (58 clumps) had increased, with the remaining 37 clumps reducing in size (mostly only marginally). We found only one new clump $\left(-29.297996^{\circ}, 31.387759^{\circ}\right)$ that was present in 2017, but not in 2006.

\subsection{Regulatory recommendations}

Sasa ramosa was not found to pose a high invasion risk in South Africa and it is recommended that this species should be delisted (See Supplementary Material 3). In contrast, Phyllostachys aurea was 
Table 1.

The evidence for the presence of alien bamboo species (taxa in Poaceae subfamily Bambusoideae) in South Africa. Scientific names were adjusted to match the nomenclature in The Plant List (www.theplantlist.org, accessed October 2019). We were unable to confirm any of these species using DNA sequencing methods. Herbarium records are based on samples in the Botanical Database of Southern Africa (http://newposa.sanbi.org/, accessed 20 June 2020 ). Current status is based on field evaluations during this study, iNaturalist observations (https://www.inaturalist.org; excluding those made by S. Canavan during fieldwork for this study) as of 14 May 2020 (*indicates “Research Grade” level). For more details see Supplementary Material 1 Terms used under 'current status' follow Blackburn et al. (2011).

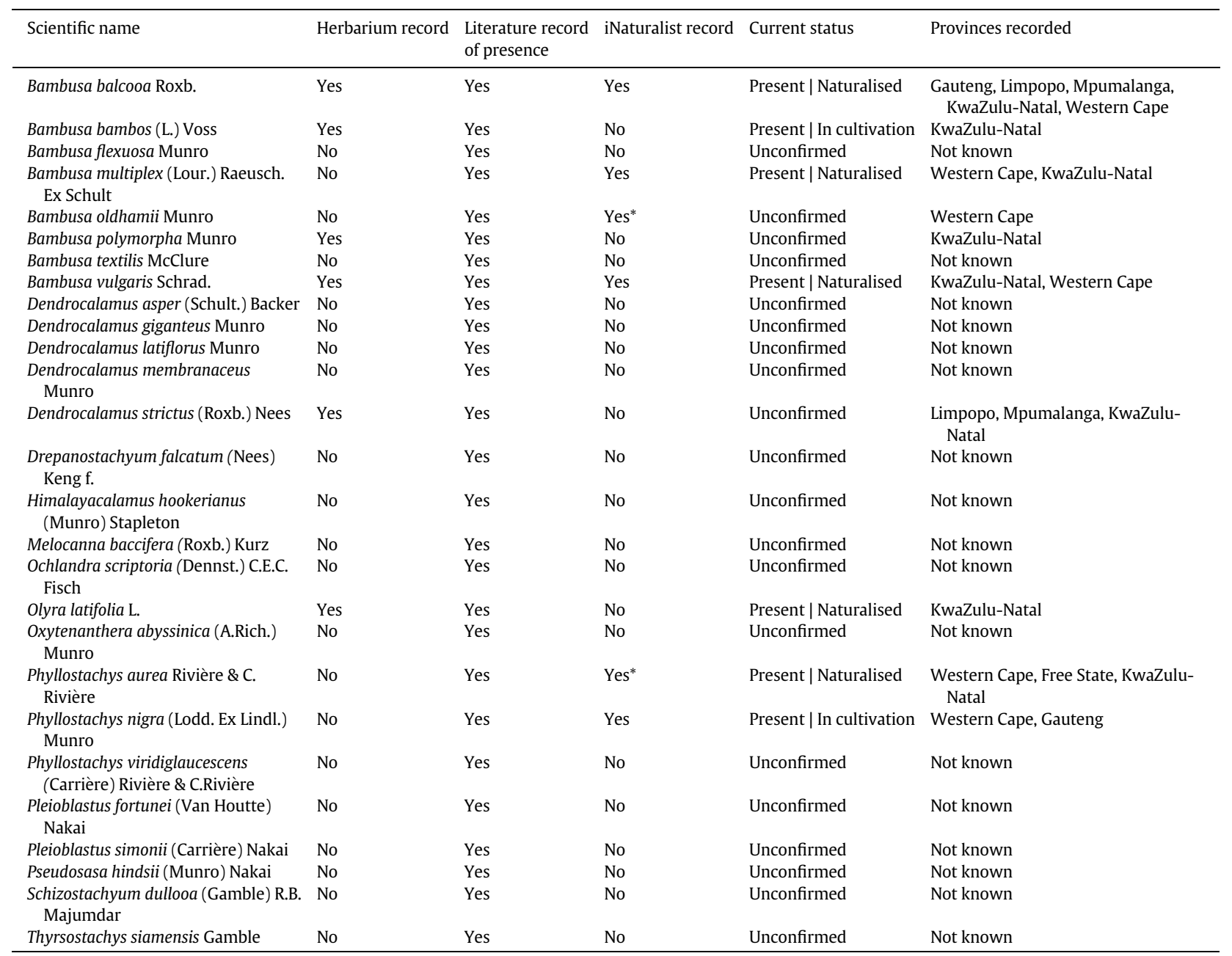

found to pose a high risk as it spreads rapidly, and forms dense monocultures that compete and crowd out other vegetation. Infrastructural damage to property is also commonly observed in urbanised areas from escaped $P$. aurea plants. These recommendations have been submitted to the South African Department of Forestry, Fisheries, and the Environment, for consideration.

\section{Discussion}

Our study confirmed that bamboos are an inherently difficult group to identify accurately and that we lack the tools required to easily differentiate the species that are present in South Africa. We also determined that there has been a marked under-reporting of the presence of bamboos around the country, particularly of the more invasive temperate species found in urban sites. We identified that the threat of certain bamboo species is not adequately reflected in current legislation relating to the management of alien species.

\subsection{Issues in identification of bamboo species}

Molecular dentification of bamboos via DNA barcoding was not possible in this study due to the low variability of the rpl16 chloroplast region. One should be cautious when comparing available reference data on GenBank, as a reliable inference would hinge upon the correct identification of reference material deposited into this database. For example, more than a third (36.2\%) of bamboo samples sequenced and uploaded to GenBank ( $n=366$ species) were synonyms, indicating an inherent issue with the poor taxonomy of listed species and a lack of resolution between frequently employed genetic markers (data downloaded: 12 Sep 2015).

Taxonomy-related errors are common in ecological datasets and are a general problem in invasion science (Pyšek et al., 2013; Murray et al., 2017; Magona et al., 2018). A recent study by Zermoglio et al. (2016) found that only $47 \%$ of 1000 scientific names of vertebrates listed in digitised biocollections were correctly validated. Such errors in identification is a serious issue for biosecurity and risk assessments. Even if targeted species are known to pose high risks, the ability to correctly identify them visually or through DNA barcoding is currently limited. Our study illustrates the need for identifying more variable gene regions that can be used to classify bamboo species accurately.

\subsection{Distribution of bamboo species in South Africa}

We found that the distribution of bamboo species in South Africa varied with the type of bamboo. This was particularly true for the 
herbaceous bamboo Olyra latifolia which is restricted to coastal forests extending from the Eastern Cape to Mozambique. Temperate bamboos are associated with urban sites or sites with high human population densities, most likely because they are popular ornamental plants that are selected for their frost-hardiness, smaller stature, and utility for screening purposes (Canavan et al., 2019b). Tropical bamboos have a more varied distribution and are found across the country and are naturalised at rural sites and are grown in gardens (Fig. 1a). The sites where tropical bamboos grow also cover a greater variation in environmental conditions. The wide distribution of tropical bamboo might be influenced, in part, by the long introduction history of these species (Fig. 1b), and multiple introduction events by different groups of people (Canavan et al., 2019b). Predictably, bamboos were not found in regions where there is low rainfall and extreme temperatures, like the Northern Cape.

The distribution and type of species reported also varied depending on the source of information. The observations from this study suggest that there is a growing popularity for temperate species in gardens which has gone undetected in national alien species databases (Fig. 1b). Temperate species pose a greater invasion risk (Lieurance et al., 2018) and there is likely also a lag between temperate species being planted in gardens and them naturalising in surrounding sites. Of the 25 temperate 'running' populations observed during our sampling, 48\% ( $n=12$ ) were found to be spreading beyond where they were planted (e.g. under perimeter walls), and/or there were clear attempts made to manage the bamboo via manual clearing or burning. In a cultivated setting temperate species are aggressive in their growth and should be carefully monitored so that they do not become naturalised in sites where they cannot be managed.

Overall, we found combining expert and public observations useful. This was possible as woody bamboos are large in size and stand out from native vegetation in South Africa, making them an easy group for public sightings. However, as for many other grasses, especially smaller species that are more discreet, invasions are often not noticed and/or are generally under reported (Visser et al., 2017).

\subsection{Evidence of increase in area, but not much spread}

The Bambusa clumps at the Nonoti site increased in size over time. However, we found no clear evidence that these bamboo populations were invasive, i.e. spread was much less than $2 \mathrm{~m}$ a year as per the invasive definition outlined in Richardson et al. (2000) for invasions via propagules spreading vegetatively. There are a number of possible reasons why we did not observe spread: (1) the surrounding site is under cultivation and highly managed, and so the bamboos clump could not spread into the adjacent landscape (although there was no evidence of the bamboos being directly targeted for clearing); (2) the bamboo is limited to riverine sites by water availability; and (3) significant spread will only occur after seed dispersal (no flowering has been observed to date), or following flood events.

Despite a lack of substantial spread, the bamboos might be having negative impacts on the river ecosystem [cf. naturalised Bambusa species along rivers in Central America (Blundell et al., 2003)]. More field research is needed to understand the effects of clumps on the ecology of the ecosystem and on the hydrology of the river system. It would also be worth investigating whether all clumps were directly planted or whether new clumps have established downriver from initial planting sites. However, currently there is no evidence that these bamboo clumps should be a high priority for management.

\subsection{Regulatory and management recommendations}

Only two taxa are listed under the NEM:BA A\&IS Regulations: Sasa ramosa and the genus Arundinaria. We found no evidence of Sasa ramosa being invasive in South Africa, or elsewhere in the world (Canavan et al., 2016). None of the three 'cane' species in the genus
Arundinaria, that are native to North America, are widely introduced or known to be invasive (Canavan et al., 2016). The listing of Arundinaria may be due to the confusing taxonomic history of the group which was only stabilised in 2009 (Triplett and Clark, 2009). Arundinaria was initially a large genus that included important woody species from Asia that have now been reassigned to other genera including Fargesia, Guadua, Pleioblastus and Pseudosasa. The listing of the genus was likely intended to target Asian temperate species of Pleioblastus and Pseudosasa which are known to be invasive. The taxonomic confusion of the group has been reflected in current regulations, and therefore the listing of bamboo species needs to be updated to better reflect current taxonomic designations and the invasion risks posed.

We propose that $S$. ramosa and Arundinaria should be removed from the list of regulated species in the NEM:BA A\&IS Regulations, and that Phyllostachys aurea should be added (See Supplementary Material 3 and 4). Many other Phyllostachys species are also highly invasive and have costly impacts (Canavan et al., 2019a). Therefore, we also recommend that the entire genus should be carefully monitored and considered for adding to the regulatory lists.

In contrast to other regions of the world, we found no evidence of major bamboo invasions in South Africa. However, there could be a lag phase or delay before invasions and impacts are seen. If large stands of bamboos were to have a gregarious seeding event, this could promote a boom in rodent populations, which is associated with the destruction of crops as well as the spread of diseases, as seen with bamboo forests in India (Lalnunnmawia et al., 2005). Secondly, the areas where bamboos are introduced and cultivated are not the habitats where impacts and invasions are typically observed. Many bamboo species are inherently weedy and can be problematic following human disturbances, even in their native ranges (e.g., timber extraction and logging), but such impacts are usually confined to forest ecosystems (Canavan et al., 2019a). In South Africa, bamboos tend to have been planted in urban areas or rural farming areas, with the exception of one site in an old plantation in KZN, bamboo infestations were not found in areas with high tree densities potentially limiting their impacts. Lastly, the species of bamboo with a longer introduction history (tropical bamboos) are less invasive than more recent introductions (temperate species, namely Phyllostachys spp.) used in horticulture so we could expect these more invasive bamboos becoming problematic in the future. Therefore, in order to maintain lower invasion rates, further plantings should avoid forested ecosystems, and not propagate species from high-risk clades.

\section{Declaration of Competing Interest}

Authors have no conflict of interest.

\section{Acknowledgments}

We acknowledge funding from the DSI-NRF Centre of Excellence for Invasion Biology (C.I.B), and the South African Department of Forestry, Fisheries, and the Environment (DFFtE), noting that this publication does not necessarily represent the views or opinions of DFFtE or its employees. DMR acknowledges support from the National Research Foundation (grant 85417) and the Oppenheimer Memorial Trust (grant 18576/03).

Attendees of the South African National 2015 Bamboo Workshop held in Stellenbosch, and the South African Alien Grass Working Group provided diverse assistance. For their valuable support with lab work and/or fieldwork we thank: Joubert Roux, Felix Sorour, Ingrid Nänni, Megan Mathese, Reshnee Lalla, Vusi Mkhize, Gerald Cebekhulu, Sharon Louwe, Menzi Nxumalo, Thabiso Cele, Kim Canavan, Shane Canavan, Adrian Sutton, Ludi Kern, Philip Ivey, and William Radloff. 


\section{Ethical approval and informed consent}

Ethical clearance to conduct the research was obtained from the National Health Research Ethics Committee (NHREC: REC-050411032) at Stellenbosch University (SU-HSD-004196). All ethical standards were adhered to. The relevant local authorities were approached for permission to conduct the research and formal, free, prior, and informed consent was obtained from all participants. Anonymity was assured.

\section{Supplementary materials}

Supplementary material associated with this article can be found in the online version at doi:10.1016/j.sajb.2020.11.027.

\section{References}

Armstrong, K.F., Ball, S.L., 2005. DNA barcodes for biosecurity: invasive species identification. Philosophical Transactions of the Royal Society B: Biological Sciences 360, 1813-1823. https://doi.org/10.1098/rstb.2005.1713.

Bamboo Phylogeny Group, 2012. An updated tribal and subtribal classification for the Bambusoideae (Poaceae). In: Proceedings of the 9th World Bamboo Congress, pp. 10-15.

Blackburn, T.M., Pyšek, P., Bacher, S., Carlton, J.T., Duncan, R.P., Jarošík, V., Wilson, J.R., Richardson, D.M., 2011. A proposed unified framework for biological invasions. Trends in Ecology \& Evolution 26, 333-339.

Blundell, A.G., Scatena, F.N., Wentsel, R., Sommers, W., 2003. Ecorisk assessment using indicators of sustainability: invasive species in the Caribbean national forest of Puerto Rico. Journal of Forestry 101, 14-19. https://doi.org/10.1093/jof/101.1.14.

Canavan, S., Kumschick, S., Le Roux, J.J., Richardson, D.M., Wilson, J.R., 2019a. Does origin determine environmental impacts? Not for bamboos. Plants, People, Planet 1, $119-128$.

Canavan, S., Richardson, D.M., Le Roux, J.J., Wilson, J.R.U., 2019b. Alien bamboos in South Africa: a socio-historical perspective. Human Ecology 47, 121-133. https:/I doi.org/10.1007/s10745-018-0041-8.

Canavan, S., Richardson, D.M., Visser, V., Le Roux, J.J., Vorontsova, M.S., Wilson, J.R.U., 2016. The global distribution of bamboos: assessing correlates of introduction and invasion. AoB Plants 9. https://doi.org/10.1093/aobpla/plw078.

Doyle, J.J., Doyle, J.L., 1990. Isolation of plant DNA from fresh tissue. Focus 12, 13-15.

GBIF, 2016. GBIF Occurrence Download http://doi.org/10.15468/dl.iq1rfa [Downloaded: 4th August 2016].

Henderson, L., Wilson, J.R.U., 2017. Changes in the composition and distribution of alien plants in South Africa: an update from the Southern African Plant Invaders Atlas. Bothalia - African Biodiversity \& Conservation 47, 1-26.

Kellogg, E.A., 2015. Monocots: Poaceae. Flowering plants, 13. Springer.

Kumschick, S., Foxcroft, L.C., Wilson, J.R., 2020a. Analysing the risks posed by biological invasions to South Africa. In: van Wilgen, BW, Measey, J, Richardson, DM, Wilson, JR, Zengeya, TA (Eds.), Biological Invasions in South Africa. Springer, Cham, Switzerland, pp. 573-595. https://doi.org/10.1007/978-3-030-32394-3_20.
Kumschick, S., Wilson, J.R.U., Foxcroft, L.C., 2020b. A framework to support alien species regulation: the risk analysis for alien taxa (RAAT). Neobiota 62, 213-239. https://doi.org/10.3897/neobiota.62.51031.

Lalnunnmawia, F., Jha, L.K., Lalengliana, F., 2005. Preliminary observations on ecological and economical impacts of bamboo flowering in Mizoram (North East India). Journal of Bamboo and Rattan 4, 317-322.

Lieurance, D., Cooper, A., Young, A.L., Gordon, D.R., Flory, S.L., 2018. Running bamboo species pose a greater invasion risk than clumping bamboo species in the continental United States. Journal for Nature Conservation 43, 39-45. https://doi.org/ 10.1016/j.jnc.2018.02.012.

Magona, N., Richardson, D.M., Le Roux, J.J., Kritzinger-Klopper, S., Wilson, J.R., 2018. Even well-studied groups of alien species might be poorly inventoried: Australian Acacia species in South Africa as a case study. NeoBiota 39, 1-29.

Milton, S.J., 2004. Grasses as invasive alien plants in South Africa: working for water. South African Journal of Science 100, 69-75.

Morris, J., Glen, H., 1978. PRECIS, the national herbarium of South Africa (PRE) computerized information system. Taxon 27, 449-462.

Murray, B.R., Martin, L.J., Phillips, M.L., Pyšek, P., 2017. Taxonomic perils and pitfalls of dataset assembly in ecology: a case study of the naturalized Asteraceae in Australia. NeoBiota 34, 1-20.

Platford, G.G., 1988. Protection against flood damage. In: Proceedings of the South African Sugar Technologists' Association.

Pyšek, P., Hulme, P.E., Meyerson, L.A., Smith, G.F., Boatwright, J.S., Crouch, N.R., Figueiredo, E., Foxcroft, L.C., Jarošík, V., Richardson, D.M., Suda, J., Wilson, J.R.U. 2013. Hitting the right target: taxonomic challenges for, and of, plant invasions. AoB Plants 5, plt042.

R Core Team, 2015. R: A Language and Environment for Statistical Computing. R Foundation for Statistical Computing, Vienna. 2012.

Richardson, D.M., Foxcroft, L.C., Latombe, G., Le Maitre, D.C., Wilson, J.R.U., 2020. The biogeography of South African terrestrial plant invasions. In: Van Wilgen, B.W., Measey, J., Richardson, D.M., Wilson, J.R.U., G.J., Zengeya, T. (Eds.), Biological Invasions in South Africa. Springer, Berlin, pp. 67-96. https://doi.org/10.1007/978-3030-32394-3_3.

Richardson, D.M., Pyšek, P., Rejmánek, M., Barbour, M.G., Panetta, F.D., West, C.J., 2000 Naturalization and invasion of alien plants: concepts and definitions. Diversity and Distributions 6, 93-107. https://doi.org/10.1046/j.1472-4642.2000.00083.x.

Rouget, M., Robertson, M.P., Wilson, J.R., Hui, C., Essl, F., Renteria, J.L., Richardson, D.M., 2016. Invasion debt-quantifying future biological invasions. Diversity and Distributions 22, 445-456.

Scheba, A., Blanchard, R., Mayeki, S., 2017. Bamboo for green development?: the opportunities and challenges of commercialising bamboo in South Africa. Human Sciences Research Council (HSRC).

Triplett, J.K., Clark, L.G., 2009. Towards a stable nomenclature for the North American temperate bamboos: Epitypification of Arundo gigantea Walt. and Arundinaria macrosperma Michx. (Poaceae). Castanea 74, 207-212.

Visser, V., Wilson, J.R., Brown, C., Canavan, K., Canavan, S., Fish, L., Le Maitre, D., Nänni, I., Mashau, C., O’Connor, T.G., Ivey, P., Kumschick, S., Richardson, D.M., 2017. Grasses as invasive plants in South Africa revisited: patterns, pathways and management. Bothalia- African Biodiversity \& Conservation 47 (2), a2169. https://doi. org/10.4102/abc.v47i2.2169.

Watts, C.D., Fisher, A.E., Shrum, C.D., Newbold, W.L., Hansen, S., Liu, C., Kelchner, S.A., 2008. The D4 set: primers that target highly variable intron loops in plant chloroplast genomes. Molecular Ecology Resources 8, 1344-1347.

Zermoglio, P.F., Guralnick, R.P., Wieczorek, J.R., 2016. A standardized reference data set for vertebrate taxon name resolution. PLoS One 11, e0146894. 